\title{
Atividade inseticida de meliáceas sobre Diabrotica speciosa (Col., Chrysomelidae)
}

\author{
Insecticidal activity of meliaceous plants on Diabrotica speciosa (Col., Chrysomelidae)
}

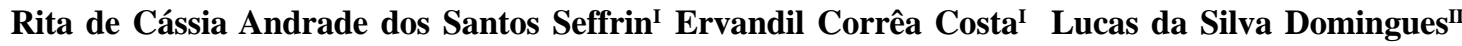 \\ Sônia Thereza Bastos Dequech ${ }^{\mathrm{I}^{*}}$ Carla Daniele Sausen ${ }^{\mathrm{II}}$
}

\section{RESUMO}

Diabrotica speciosa é um inseto-praga polífago e seu controle demanda um elevado número de aplicações de inseticidas. $O$ uso de extratos de plantas da família Meliaceae, com atividade inseticida, surge como uma alternativa promissora de controle. Neste trabalho, a ação de extratos aquosos de frutos verdes, de pecíolos com caule, de folíolos $e$ de casca de Melia azedarach var azedarach (cinamomo) a $10 \%(p / v)$ e do NIM-I-GO a $10 \mathrm{~mL} \mathrm{~L} \mathrm{~L}^{-1}$ (produto comercial de óleo de nim emulsionado) foi avaliada no controle de insetos adultos de D. speciosa em cultivos de pepino (Cucumis sativus) e de feijão-de-vagem (Phaseolus vulgaris) em estufa plástica. Foi utilizado o inseticida DECIS 25CE a $0,3 \mathrm{~mL} \mathrm{~L}^{-1}$ como padrão. Foi realizada também a avaliação da estatura de plantas, após o início da colheita, e da produção. Extratos de frutos verdes, de folíolos e de pecíolos com caule de cinamomo são promissores no controle de D. speciosa, em cultivos de pepino, e apenas de frutos verdes no de feijão-de-vagem, representando alternativas de controle desses crisomelídeos. $O$ uso desses extratos não resultou em alteração significativa na estatura e na produção das plantas, ao serem comparadas com a testemunha.

Palavras-chave: Melia azedarach, plantas inseticidas, Cucumis sativus, Phaseolus vulgaris.

\section{ABSTRACT}

Diabrotica speciosa is a polyphagous insect-pest and its control demands a great deal of insecticides applications. The use of extracts from Meliaceae family plants, with insecticidal activity, appears as a promising control alternative. The present work aimed to evaluate the control action of aqueous extract from Melia azedarach var. azedarach (chinaberry) - unripe fruits, petioles with stalk, leaflets and barks - at $10 \%(\mathrm{p} / \mathrm{v})$ each one, compared with NIM-I-GO at $10 \mathrm{~mL} \mathrm{~L} \mathrm{~L}^{-1}$ (emulsified commercial oil of neem) and DECIS $25 C E$ at $0.3 m L L^{-1}$, as a standard treatment, over adult insects of D. speciosa on cucumber (Cucumis sativus) and string beans (Phaseolus vulgaris) cultivated in greenhouse. It was evaluated as well the height of plants, after the beginning of the harvest, and the production. Extracts of unripe fruits, leaflets and petioles with stalk of chinaberry are flattering in the control of $\mathbf{D}$. speciosa in cultures of cucumber, and only unripe fruits in string beans. Therefore, these extracts can be used as alternatives in control of this chrysomelid. The use of these extracts did not result in significant change in stature and the production of the plants, when compared with the control.

Key words: Melia azedarach, insecticidal plants, Cucumis sativus, Phaseolus vulgaris.

\section{INTRODUÇÃO}

As pesquisas envolvendo plantas inseticidas evoluíram significativamente nas últimas décadas, sendo que os resultados obtidos com extratos de Azadirachta indica A. Juss., conhecido como nim, têm estimulado estudos com outras plantas da família Meliaceae, que se destaca pela comprovada atividade biocida. O cinamomo (Melia azedarach L.) é uma espécie promissora, pois, além de apresentar ação contra os insetos, se encontra adaptada a regiões mais frias do país, onde o nim não apresenta bom desenvolvimento (MARTINEZ, 2002).

O uso de compostos de origem vegetal pode vir a tornar-se uma alternativa de controle de insetospraga, principalmente em pequenas áreas de produção, como olerícolas cultivadas em estufas plásticas. Esta prática representa a possibilidade de colheitas em períodos de entressafra e proporciona maior rentabilidade e proteção das culturas a fatores meteorológicos adversos. Contudo, este ambiente, com temperaturas elevadas e grande disponibilidade de alimento, torna-se propício para o crescimento de

IDepartamento de Defesa Fitossanitária, Universidade Federal de Santa Maria (UFSM), 97105-900, Santa Maria, RS, Brasil. Email: soniabd@terra.com.br.*Autor para correspondência.

IICurso de Agronomia, UFSM, Santa Maria, RS, Brasil. 
populações de insetos, como Diabrotica speciosa (Germar, 1824) (Col., Chrysomelidae), principal espécie de inseto-praga de algumas olerícolas no Sul do Brasil (GASSEN, 1989).

D. speciosa é uma espécie polífaga, de ampla disseminação (KRYSAN, 1986), sendo que, a partir de 1920, a presença de insetos adultos, conhecidos por vaquinhas, foi referida em quase todos os Estados brasileiros (MILANEZ, 1995). Segundo estudos realizados por HOHMANN \& CARVALHO (1989), o consumo médio de folhas de feijão por $\boldsymbol{D}$. speciosa é de $0,70 \mathrm{~cm}^{2}$ por dia. Dados evidenciam que, na fase inicial da cultura (uma semana após a emergência), dois insetos por planta já podem provocar desfolha de até 16\% em 24 horas de alimentação (SILVA et al., 2003). O controle deste inseto é realizado, basicamente, por meio de freqüentes pulverizações com inseticidas sintéticos (MILANEZ, 1995).

Na busca de espécies de plantas com ação no controle de $\boldsymbol{D}$. speciosa, $\boldsymbol{M}$. azedarach vem sendo citada por alguns autores. Extratos de folhas obtidos por prensagem e extrato aquoso de polpa de frutos (25 frutos $100 \mathrm{~mL}^{-1}$ de água) causaram, respectivamente, $89 \%$ e $97,5 \%$ de mortalidade de $\boldsymbol{D}$. speciosa. O extrato de frutos reduziu o consumo em $8 \%$ e o extrato da polpa de frutos suprimiu totalmente o consumo alimentar, em laboratório (CARVALHO \& CASTRO, 1987). GRAINGE \& AHMED (1988) citam extratos de M. azedarach como inibidores da alimentação para várias espécies de insetos. CARVALHO \& FERREIRA (1990) testaram a redução de consumo foliar causada por extratos de $\boldsymbol{M}$. azedarach obtidos em diferentes épocas do ano, concluindo que os frutos verdes colhidos em janeiro e março reduziram em 100\% o consumo foliar. Estudos que evidenciaram a atividade fagodeterrente de extratos de folhas, de pecíolos, de flores e de frutos de $\boldsymbol{M}$. azedarach sobre $\boldsymbol{D}$. speciosa foram realizados por VENTURA \& ITO (2000).

Em função da maioria dos trabalhos terem sido realizados em condição de laboratório e da ausência de resultados em cultivos em estufa plástica, foi realizado o presente trabalho. O trabalho teve como objetivo, portanto, investigar a eficiência de extratos aquosos de diferentes estruturas vegetais de cinamomo, além do produto comercial de óleo de nim emulsionado marca NIM-I-GO, no controle de insetos adultos de $\boldsymbol{D}$. speciosa, em pepino (Cucumis sativus) e feijão-devagem (Phaseolus vulgaris) cultivados em estufa plástica, visando obter uma alternativa viável de controle desses crisomelídeos.

\section{MATERIAL E MÉTODOS}

Os trabalhos foram realizados no anode de 2004, na Universidade Federal de Santa Maria, em Santa Maria, RS, em estufa plástica pertencente ao Departamento de Defesa Fitossanitária.
O material botânico que originou os extratos aquosos foi coletado na área experimental do Departamento de Fitotecnia da Universidade Federal de Santa Maria. As coletas foram realizadas de sete a dez dias antes de cada aplicação dos tratamentos. Para preparo dos extratos, seguiu-se a metodologia proposta por BOGORNI (2003). Primeiramente, procedeu-se à secagem de folíolos e de casca de $\boldsymbol{M}$. azedarach var. azedarach à temperatura ambiente e após à trituração em liquidificador, até a obtenção de um pó. Frutos verdes e pecíolos com caule foram triturados no liquidificador sem a secagem. Foi utilizada água como solvente, para a extração dos compostos polares, e os extratos foram mantidos a $10^{\circ} \mathrm{C}$ por 24 horas. Antes da utilização nos experimentos, os extratos foram coados com tecido tipo voal.

Em 11 de março foi semeado o primeiro cultivo de pepino Hibrido Pioneiro em bandejas de isopor contendo substrato vegetal. As mudas foram protegidas com tela milimétrica. Em 30 de março foi realizado o transplante para os canteiros, com espaçamento de 0,30m entre plantas na linha e 1,0m entre as linhas. As plantas foram distribuídas em quatro blocos, cada bloco com cinco parcelas, sendo cada parcela composta por 12 plantas.

Os tratamentos utilizados foram extratos aquosos a $10 \%(\mathrm{p} / \mathrm{v})$ de folíolos, de casca e de frutos verdes de $\boldsymbol{M}$. azedarach var. azedarach, além da testemunha (água). Foi utilizado como padrão o inseticida sintético DECIS 25CE $\left(0,3 \mathrm{~mL} \mathrm{~L}^{-1}\right)$. Em todos os tratamentos foi adicionado óleo vegetal a $0,1 \%$ para melhorar a aderência dos extratos nas folhas e reduzir a degradação dos compostos do extrato (BOGORNI, 2003) em função da exposição à radiação solar e às altas temperaturas dentro da estufa.

Em 24 de agosto foi semeado o segundo cultivo de pepino, sendo que o transplante das mudas foi realizado em 14 de setembro. Foram utilizados os mesmos procedimentos do cultivo anterior, referentes à cultivar, às técnicas de semeadura, ao número de blocos e parcelas e aos espaçamentos. Neste cultivo, cada parcela foi composta por sete plantas.

O extrato mais eficiente no primeiro cultivo (frutos verdes de $\boldsymbol{M}$. azedarach var. azedarach) foi comparado com o extrato de pecíolos com caule de cinamomo, o inseticida sintético DECIS 25CE, o produto comercial de óleo de nim emulsionado marca NIM-I$\mathrm{GO}\left(10 \mathrm{~mL} \mathrm{~L}^{-1}\right)$ e a testemunha (água). Foram utlizados o DECIS e o óleo vegetal nas mesmas concentrações do ensaio anterior.

Em 09 de agosto foi semeado o feijão-devagem da variedade Torino Macarrão Trepador diretamente em canteiros. As plantas foram distribuídas em quatro blocos, com cinco parcelas em cada bloco, com espaçamento entre plantas de 0,2m e 1,0m entre linhas, sendo cada parcela composta por 10 plantas. Fez-se a aplicação dos mesmos extratos utilizados na cultura do pepino no segundo cultivo. Em todos os 
cultivos, o delineamento experimental utilizado foi de blocos ao acaso.

No primeiro e no segundo cultivo de pepino, fez-se o levantamento quantitativo dos adultos de $\boldsymbol{D}$. speciosa por meio da contagem do número de insetos adultos na parte aérea das plantas, avaliando-se duas plantas por parcela, em três observações semanais. Na cultura do feijão-de-vagem, fez-se a mesma contagem, porém em quatro plantas por parcela, com o mesmo número de avaliações semanais.

Após o início da infestação por $\boldsymbol{D}$. speciosa, foi iniciada a aplicação semanal dos tratamentos, totalizando nove aplicações no primeiro cultivo de pepino e oito aplicações tanto no segundo cultivo de pepino quanto no cultivo de feijão-de-vagem. A periodicidade dos tratamentos baseou-se em observação realizada por CARVALHO \& FERREIRA (1990), que verificaram que a ação antialimentar de extratos aquosos de frutos e de folhas de cinamomo é reduzida a partir do quinto dia após a aplicação.

No primeiro cultivo de pepino, a colheita foi iniciada em 3 de maio e finalizada em 24 de maio; no segundo cultivo de pepino e no cultivo de feijão-devagem, a colheita foi realizada de 3 a 23 de novembro. Foi realizada, ainda, a medição da estatura de quatro plantas por parcela, após o início da colheita, com uma trena metálica. Frutos/vagens foram colhidos quando apresentaram a maturação ideal para o consumo "in natura”, para avaliação da produção.

Os dados obtidos foram submetidos à análise da variância, com as médias comparadas pelo Teste de Tukey em nível de significância de 5\%. A eficiência de controle dos tratamentos foi calculada por meio da fórmula de Abbott (ABBOTT, 1925).

\section{RESULTADOS E DISCUSSÃO}

A infestação de $\boldsymbol{D}$. speciosa teve início na fase de floração, nos três cultivos, sendo a mesma ocorrência encontrada por GIORDANI et al. (1996), na cultura do pepino.

Entre os extratos aquosos testados, o de frutos verdes de $\boldsymbol{M}$. azedarach var. azedarach resultou numa maior eficiência no controle de $\boldsymbol{D}$. speciosa, nos três cultivos avaliados. Porém, além deste, o uso de extratos de folíolos e de pecíolo com caule no primeiro e no segundo cultivo de pepino, respectivamente, também resultou numa diminuição significativa do número de vaquinhas, quando comparados com a testemunha (Tabela 1). Bons resultados com o uso de frutos de cinamomo foram obtidos por CARVALHO \& CASTRO (1987) e CARVALHO \& FERREIRA(1990), porém em ensaios realizados em laboratório. BOGORNI (2003) observou que o uso de extrato aquoso a 5\% de frutos das meliáceas Trichilia pallens e Trichilia palida foi efetivo para o controle de Spodoptera frugiperda (J.E. Smith) (Lep., Noctuidae).
Os frutos verdes exercem ação fagodeterrente, com os insetos passando a se alimentar da testemunha. No extrato aquoso destas estruturas, há a formação de uma espuma devido à presença de saponinas, que são solúveis em água e são um indicativo de perigo recebido pelos insetos após o início da alimentação, na forma de gosto amargo (SAITO \& LUCHINI, 1998). Extratos aquosos de pecíolos com caule de $\boldsymbol{M}$. azedarach também possuem ação fagodeterrente, tendo esta ação sido observada por CARVALHO \& FERREIRA(1990) e por CARPINELLA et al. (2003).

Em relação às avaliações da estatura das plantas e da produção, em ambos os cultivos de pepino, pode-se observar que o uso de todos os extratos não resultou em diferença estatisticamente significativa em relação à testemunha. Porém, no primeiro cultivo, extratos de frutos verdes de cinamomo causaram uma redução significativa tanto da estatura das plantas quanto da produção de frutos, quando comparados aos valores obtidos com o uso do inseticida padrão (DECIS). Tal fato conduz a uma tendência de efeito fitotóxico deste extrato (Tabela 2). Na cultura de feijão-

Tabela 1 - Número médio de insetos adultos de Diabrotica speciosa e eficiência de controle de extratos aquosos $(10 \% \mathrm{p} / \mathrm{v})$ de estruturas vegetais de Melia azedarach var azedarach (cinamomo), NIM-I-GO e Decis 25 CE, em cultivos em estufa plástica. Santa Maria-RS, 2004.

\begin{tabular}{|c|c|c|}
\hline tratamentos & médias $^{1}$ & $\begin{array}{c}\text { eficiência } \\
\text { (\%) }\end{array}$ \\
\hline \multicolumn{3}{|c|}{ primeiro cultivo de pepino } \\
\hline testemunha & $38,00 \mathrm{a}$ & \\
\hline casca de cinamomo & $27,25 \mathrm{ab}$ & 28,28 \\
\hline folíolos de cinamomo & $26,50 \mathrm{bc}$ & 30,26 \\
\hline frutos verdes de cinamomo & $16,00 \mathrm{c}$ & 57,89 \\
\hline Decis $25 \mathrm{CE}$ & $3,50 \mathrm{~d}$ & 90,78 \\
\hline \multicolumn{3}{|l|}{ Coeficiente de variação: 21,73 } \\
\hline \multicolumn{3}{|c|}{ segundo cultivo de pepino } \\
\hline testemunha & 3,24 a & \\
\hline NIM-I-GO & $2,67 \mathrm{ab}$ & 17,59 \\
\hline pecíolo com caule de cinamomo & $1,90 \mathrm{bc}$ & 41,35 \\
\hline frutos verdes de cinamomo & 1,59 c & 50,92 \\
\hline Decis $25 \mathrm{CE}$ & $1,39 \mathrm{c}$ & 57,09 \\
\hline \multicolumn{3}{|l|}{ Coeficiente de variação: 11,35 } \\
\hline \multicolumn{3}{|c|}{ cultivo de feijão-de-vagem } \\
\hline testemunha & 3,10 a & \\
\hline NIM-I-GO & $2,04 \mathrm{ab}$ & 34,19 \\
\hline pecíolo com caule de cinamomo & $2,00 \mathrm{ab}$ & 35,48 \\
\hline frutos verdes de cinamomo & $1,95 \mathrm{~b}$ & 37,09 \\
\hline Decis 25 CE & $1,54 \mathrm{~b}$ & 50,32 \\
\hline Coeficiente de variação: 23,55 & & \\
\hline
\end{tabular}

${ }^{1}$ Médias não seguidas pela mesma letra diferem

significativamente pelo teste de Tukey a 5\% de significância. 
Tabela 2 - Avaliação da estatura média (m) e da produção média (kg) de plantas de pepino tratadas com extratos aquosos (10\% p/v) de estruturas vegetais de Melia azedarach var azedarach (cinamomo), NIM-I-GO e Decis 25 CE em cultivos em estufa plástica. Santa Maria-RS, 2004.

\begin{tabular}{|c|c|c|c|c|}
\hline \multirow{2}{*}{ Tratamento } & \multicolumn{2}{|c|}{-----------------primeiro cultivo------------------ } & \multicolumn{2}{|c|}{------------------segundo cultivo------------------ } \\
\hline & estatura média $(\mathrm{m})^{1}$ & produção média $(\mathrm{kg})^{1}$ & estatura média (m) & produção média (kg) \\
\hline DECIS 25 CE & $1,98 \mathrm{a}$ & 10,74 a & $1,57 \mathrm{NS}$ & $5,32 \mathrm{NS}$ \\
\hline NIM-I-GO & & & 1,48 & 3,98 \\
\hline pecíolos com caule de cinamomo & & & 1,45 & 5,07 \\
\hline casca de cinamomo & $1,66 \mathrm{ab}$ & $7,39 \mathrm{ab}$ & & \\
\hline folíolos de cinamomo & 1,86 a & $6,86 \mathrm{ab}$ & & \\
\hline testemunha & $1,67 \mathrm{ab}$ & $6,58 \mathrm{ab}$ & 1,38 & 2,95 \\
\hline frutos verdes de cinamomo & $1,28 \mathrm{~b}$ & $5,84 \mathrm{~b}$ & 1,36 & 2,54 \\
\hline
\end{tabular}

${ }^{1}$ Médias não seguidas pela mesma letra diferem significativamente pelo teste de Tukey a 5\% de significância.

NS: não-significativo.

de-vagem, não houve diferença significativa para os parâmetros analisados entre todos os tratamentos (Tabela 3). Nessa fabácea, extratos de frutos verdes não afetaram a altura das plantas e a produção de vagens. Esta observação está de acordo com o exposto por MARTINEZ (2002), em que cinco pulverizações semanais com extratos aquosos de frutos de cinamomo a 30\% (p/v), em feijoeiro, não resultaram em nenhum tipo de fitotoxicidade.

Portanto, de acordo com as condições em que foi desenvolvido o presente trabalho, conclui-se que extratos aquosos de frutos verdes, de folíolos e de pecíolos com caule de M. azedarach var. azedarach a $10 \%$ (p/v) são promissores no controle de $\boldsymbol{D}$. speciosa, em cultivos de pepino, e apenas de frutos verdes no de feijão-de-vagem, representando alternativas de controle desse inseto-praga. O uso desses extratos não resultou em alteração significativa na estatura e na produção média das plantas, em comparação com a testemunha.

Tabela 3 - Avaliação da estatura média (m) e da produção média (kg) de plantas de feijão-de-vagem tratadas com extratos aquosos $(10 \% \mathrm{p} / \mathrm{v})$ de estruturas vegetais de Melia azedarach var azedarach (cinamomo), NIM-IGO e Decis 25 CE em cultivos em estufa plástica. Santa Maria-RS, 2004.

\begin{tabular}{lcc}
\hline Tratamentos & $\begin{array}{c}\text { estatura } \\
\text { média (m) }\end{array}$ & $\begin{array}{c}\text { produção } \\
\text { média (kg) }\end{array}$ \\
\hline DECIS 25 CE & $2,58 \mathrm{NS}$ & 3,62 NS \\
NIM-I-GO & 2,68 & 3,15 \\
pecíolos com caule de cinamomo & 2,66 & 3,93 \\
testemunha & 2,61 & 3,12 \\
frutos verdes de cinamomo & 2,55 & 3,40 \\
\hline
\end{tabular}

NS: não-significativo.

\section{REFERÊNCIAS}

ABBOTT, W.S. A method of computing the effectiveness of an insecticide. Journal of Economic Entomology, v.18, p.265-267, 1925.

BOGORNI, P.C. Efeito de extratos aquosos de Trichilia pallens e Trichilia palida no controle de Spodoptera frugiperda (J.E. Smith) em milho. 2003. 65f. Tese (Doutorado em Ciências) - Escola Superior de Agricultura Luiz de Queiroz, Universidade de São Paulo.

CARPINELLA, M.C. et al. Antifeedant and insecticides properties of limonoid from Melia azedarach (Meliaceae) with potencial use for pest management. Journal of Agricultural and Food Chemistry, v.51, p.369-374, 2003.

CARVALHO, S.M.; CASTRO, B.R.R. Efeito de plantas tóxicas no controle da vaquinha Diabrotica speciosa Germar em laboratório. In: REUNIÃO NACIONAL DE PESQUISA EM FEIJÃO, 2., 1987, Goiânia,GO. Anais... EMBRAPA/ CNPAF, 1987. p.49.

CARVALHO, S.M.; FERREIRA, D.T. Santa Bárbara contra a vaquinha. Ciência Hoje, v.4, n.65, p.65-67, 1990.

GASSEN, D.N. Insetos subterrâneos prejudiciais às culturas no sul do Brasil. Passo Fundo: EMBRAPA/CNPT, 1989. 72p.

GIORDANI, R. et al. Levantamento de insetos-pragas na cultura do pepino em estufa plástica. In: CONGRESSO BRASILEIRO DE INICIAÇÃO CIENTÍFICA EM CIÊNCIAS AGRÁRIAS, 16., 1996, Santa Maria, RS. Anais... Santa Maria: Universidade Federal de Santa Maria, 1996. p.125.

GRAINGE, M.; AHMED, S. Handbook of plants with pest control properties. New York: Jonh Wiley, 1988. 470p.

HOHMANN, C.L.; CARVALHO, S.M. Pragas e seu controle. In: IAPAR. O feijão no Paraná. Londrina: IAPAR, 1989. p. 217-246.

KRYSAN, J.L. Introducion, biology, distribution and identification of pest Diabrotica. In: KRYSAN, J.L.; MILLER,

Ciência Rural, v.38, n.7, out, 2008. 
T.A. Methods for study of pest Diabrotica. New York: Springer-Verlag, 1986. p.1-23.

MARTINEZ, S.S. O Nim-Azadirachta indica: natureza, usos múltiplos, produção. Londrina: Instituto Agronômico do Paraná (IAPAR), 2002. 142p.

MILANEZ, J.M. Técnicas de criação e bioecologica de Diabrotica speciosa Germar (1824) (Coleoptera: Chrysomelidae). 1995. 102f. Tese (Doutorado em Ciências) - Escola Superior de Agricultura Luiz de Queiroz, Universidade de São Paulo.
SAITO, M.L.; LUCHINI, F. Substâncias obtidas de plantas e a procura por praguicidas eficientes e seguros ao meio ambiente. Jaguariúna: EMBRAPA/CNPMA, 1998. 46p.

SILVA, A.L. et al. Avaliação do efeito da desfolha na cultura do feijoeiro (Phaseolus vulgaris). Pesquisa Agropecuária Tropical, v.33, n.2, p.83-87, 2003.

VENTURA, M.U.; ITO, M. Antifeedant activity of Melia azedarach L. extracts to Diabrotica speciosa (Genn.) (Coleoptera: Chrysomelidae) beetles. Brazilian Archives of Biology and Technology, v.22, n.2, p.215-219, 2000. 